\title{
Decreased Serum Selenium Levels of COVID-19 Patients in Comparison with Healthy Individuals
}

\author{
Ommolbanin Younesian ${ }^{1} \cdot$ Behnaz Khodabakhshi ${ }^{2,3} \cdot$ Nafiseh Abdolahi $^{4} \cdot$ Alireza Norouzi $^{3} \cdot$ Nasser Behnampour $^{5}$. \\ Sara Hosseinzadeh ${ }^{1} \cdot$ Seyedeh Somayeh Hosseini Alarzi ${ }^{1} \cdot$ Hamidreza Joshaghani $^{1}$
}

Received: 31 March 2021 / Accepted: 16 June 2021 / Published online: 1 July 2021

(c) The Author(s), under exclusive licence to Springer Science+Business Media, LLC, part of Springer Nature 2021

\begin{abstract}
Background Severe Acute Respiratory Syndrome Coronavirus-2 (SARS-CoV-2) is the cause of the COVID-19 pandemic and is the cause of increased mortality, especially among elderly patients and those who have severe complications, such as chronic pulmonary obstruction, hypertension, diabetes, and cancer. Nutrition, especially micronutrients, plays an important role in reducing mortality and complications from COVID-19 because micronutrients strengthen our immune system and nutritional status is an important factor that affects the outcome of patients with COVID-19. Among micronutrients, selenium has an important effect on both intrinsic and acquired immunity. Host selenium deficiency affects the viral genome and increases the virulence of viruses. We have investigated the serum selenium levels in COVID-19 patients and healthy control individuals.

Methods A total of 50 patients with COVID-19 infection were included in this study. During hospitalization, 13 patients died (non-survivor group) and 37 patients recovered (survivor group). We assessed the serum selenium levels in 50 COVID-19 patients and 50 healthy individuals by Agilent SpectrAA-240 Z atomic absorption spectrometer.

Results The serum selenium level was significantly lower in COVID-19 patients (77. $8 \pm 13.9 \mu \mathrm{g} / \mathrm{L}$ ) as compared to healthy control individuals $(91.7 \pm 16.7 \mu \mathrm{g} / \mathrm{L})$, but there was no significant difference between the survivor and non-survivor groups. Also, there was no significant relationship between serum selenium levels and laboratory findings of COVID-19 patients. Conclusions These results suggest that decreased serum selenium levels may be a risk factor for the COVID-19 infection, but there was no significant relationship between selenium and severity and mortality of COVID-19 disease.
\end{abstract}

Keywords COVID-19 $\cdot$ Micronutrient $\cdot$ Selenium $\cdot$ Immune response $\cdot$ Inflammation

Hamidreza Joshaghani

joshaghani@goums.ac.ir

1 Laboratory Sciences Research Center, Golestan University of Medical Sciences, 60 Kola Road, Falsafi Building, Gorgan, Iran

2 Infectious Diseases Research Center, Golestan University of Medical Sciences, Gorgan, Iran

3 Golestan Research Center of Gastroenterology and Hepatology, Golestan University of Medical Sciences, Gorgan, Iran

4 Golestan Rheumatology Research Center, Golestan University of Medical Science, Gorgan, Iran

5 Department of Biostatistics, Health Management and Social Development Research Center, Golestan University of Medical Sciences, Gorgan, Iran

\section{Introduction}

Severe Acute Respiratory Syndrome Coronavirus-2 (SARSCoV-2) is the cause of the COVID-19 pandemic and is the cause of increased mortality, especially among elderly subjects and those who have severe complications, such as chronic pulmonary obstruction, hypertension, diabetes, and cancer $[1,2]$. This virus is a single-stranded RNA whose complex metabolism is comparable to other RNA viruses [3, 4]. COVID-19 is a systemic disease with obvious respiratory symptoms. Also, secondary symptoms associated with mortality from the disease include systemic micro thrombosis (a feature of hemorrhagic fever viruses) [5] and heart failure such as myocardial injury (the main feature of Coxsackievirus infection) [6]. The severity of the disease is related to an overreaction of the body's immune system with the release of various cytokines and chemokines "cytokine storm" [7]. 
Since no effective treatment for COVID-19 has been identified, all potential therapies, mitigation interventions, and prevention strategies that may reduce the incidence or severity of the infection are critical. Nutrition, especially micronutrients, plays an important role in reducing mortality and complications from COVID-19 because micronutrients strengthen our immune system and nutritional status is an important factor that affects the outcome of patients with COVID-19 [8]. Among micronutrients, selenium has an important effect on both intrinsic and acquired immunity. Selenium enhances the function of CD4+ T cell and B cell and also increases the activity of natural killer (NK) cells [9]. Host selenium deficiency affects the viral genome and increases the virulence of viruses such as coxsackievirus B3 and influenza A [10, 11]. Selenium supplementations have direct antiviral activity in an animal model of the coxsackievirus and influenza. These compounds also have a therapeutic effect on human viral infections such as HIV-1 and hantavirus infections [12]. Like other RNA viruses, SARS-CoV-2 may be affected by selenium status. Activation of nuclear factor kappaB (NF-kB) signaling pathway in various families of viruses increased viral replication and inhibited apoptosis of the virus. This signaling pathway plays an important role in the progression of the COVID19. Selenium and selenoproteins inhibit NF- $\kappa B$ and decrease viral replication [13]. Blood coagulation disorders that lead to the formation of micro-clots are one of the leading causes of death in patients with COVID-19. Selenium reduces the blood clots forming in the blood vessels [14].

Considering the association of selenium with RNA viruses and mechanisms related to COVID-19, we have investigated the serum selenium levels in COVID-19 patients and healthy control individuals to understand the association between selenium levels and severity and mortality of COVID-19 disease.

\section{Materials and Methods}

\section{Study Design}

This cross-sectional study, by the ethical principles and the national norms and standards for conducting medical research in Iran, was approved by the Golestan University of medical sciences with an ethics code (IR.GOUMS. REC.1399.297). With the informed consent and before starting treatment of patients, blood samples were taken from all patients admitted to Sayyad Shirazi hospital (academic hospital in Gorgan, Golestan University of medical sciences) who were suspected of having COVID-19. All blood samples were then centrifuged to separate the serum. After centrifugation, the serum samples were stored at $-80^{\circ} \mathrm{C}$ (Sayyad Shirazi hospital) and sent on dry ice to a Kavosh medical laboratory for analysis (Gorgan, Iran). Patients whose COVID-19 was confirmed by the Real-time PCR were included in this study. Children younger than 18 years of age were excluded. The clinical condition of the COVID-19 patients and the results of white blood cell count, lymphocytes, neutrophils, neutrophil-to-lymphocyte ratio (NLR), platelets, lactate dehydrogenase (LDH), hospitalization time, and age were extracted from electronic medical records. The healthy control group consisted of 50 individuals who were matched with the patient group in terms of age and sex.

\section{Selenium Analysis}

Concentrations of selenium have been analyzed by Agilent SpectrAA-240 Z atomic absorption spectrometer equipped with Zeeman background correction and fitted with a PSD120 sampler by graphite furnace and graphite tubes with integrated L'vov platform. The measured wavelength of selenium was $196.0 \mathrm{~nm}$. The serum samples were prepared according to the method described by Jacobson and Lockitch [15]. Briefly, the samples were diluted with reducing agent including ascorbic acid, Triton X-100, and Antifoam $\mathrm{B}$ emulsion, and then, palladium chloride as a matrix modifier was added.

\section{Statistical Analysis}

Statistical analysis in this study was performed using SPSS16. Shapiro-Wilk test was used to investigate the normal distribution of data. Data on age, hospitalization time, and laboratory findings were expressed as medians and the interquartile range (IQR), whereas the value of serum selenium level was expressed as means and the respective standard deviations (Mean $\pm \mathrm{SD}$ ). $T$-test was used to compare the two groups. Correlations assessment was performed by Spearman's correlation test. $p$-values $<0.05$ were considered significant.

\section{Results}

\section{Patient Characteristics}

A total of 50 patients with COVID-19 infection were included in this study. During hospitalization, 13 patients died (non-survivor group) and 37 patients recovered (survivor group). The median time to recovery and death was 6 and 12 days, respectively. The median age of the 50 COVID19 patients was 56.0 years (interquartile range $43-70$ years), and most patients were male. The differences in age, lymphocyte count, platelet count, neutrophil-to-lymphocyte ratio, and lactate dehydrogenase on admission between the 
survivor and non-survivor group were statistically significant $(p<.05)$ (Table 1$)$.

\section{Selenium Status Analysis}

The mean serum selenium level in COVID-19 patients was $77.8 \pm 13.9 \mu \mathrm{g} / \mathrm{L}$, while it was $91.7 \pm 16.7 \mu \mathrm{g} / \mathrm{L}$ in the healthy control group. The difference in selenium level between the two groups was statistically significant $(p<.05)$ (Table 2). In COVID-19 patients, serum selenium levels were higher in males than in females, while in the healthy control group, it was higher in women than in men. In both groups, this difference was not significant $(p>.05)$.

In the comparison between the survivor and non-survivor groups, the mean serum selenium level in the survivor group was $77.9 \pm 14.3 \mu \mathrm{g} / \mathrm{L}$, which was not significantly different from the mean serum selenium level in the non-survivor group, which was $77.2 \pm 12.3 \mu \mathrm{g} / \mathrm{L}(p>.05)$.

No statistically significant correlation was found between age and serum selenium level in COVID-19 patients and the healthy control group $(r=0.268 ; p>.05)$. There was no significant relationship between selenium and prognostic factors of severe COVID-19 disease such as lymphopenia $(r=-0.298 ; p>.05)$, thrombocytopenia $(r=-0.016 ; p>.05)$, leukocytosis $(r=-0.019 ; p>.05)$, neutrophil-to-lymphocyte
Table 2 Comparison of selenium levels between the COVID-19 patients and the healthy control group

\begin{tabular}{llll}
\hline & COVID-19 patients & Healthy control group & $p$ value \\
\hline Serum selenium $[\mu \mathrm{g} / \mathrm{L}]$, mean $\pm \mathrm{SD}$ & & \\
Total & $77.8 \pm 13.9$ & $91.7 \pm 16.7$ & 0.001 \\
Female & $77.8 \pm 16.7$ & $95.8 \pm 18.8$ & \\
Male & $77.8 \pm 12$ & $88.4 \pm 14.5$ & \\
\hline
\end{tabular}

$S D$ standard deviation. *Significant group difference at $p<0.05$. Data were expressed as mean $\pm \mathrm{SD}$

ratio $(r=0.026 ; p>.05)$, lactate dehydrogenase $(r=-0.274$; $p>.05)$, and hospitalization time $(r=0.152 ; p>.05)$.

\section{Discussion}

In this study, our results showed that serum selenium levels in COVID-19 patients were lower than in the healthy control group. Our results suggested that decreased serum selenium levels may be a risk factor for the COVID-19 infection, and these results were consistent with other studies. A study in Germany reported that the serum level of selenium was meaningfully lower in the surviving
Table 1 Clinical characteristics of the COVID-19 patients

\begin{tabular}{|c|c|c|c|}
\hline & Survivor $(n=37)$ & Non-survivor $(n=13)$ & $p$ value \\
\hline Age (years), median with (IQR) & $49(42-66)$ & $72(65-77)$ & $<0.001^{*}$ \\
\hline \multicolumn{4}{|l|}{ Sex, no. $(\%)$} \\
\hline Female & $16(43.2 \%)$ & $3(22.2 \%)$ & \multirow[t]{2}{*}{$<0.001^{*}$} \\
\hline Male & $21(56.8 \%)$ & $10(77.8 \%)$ & \\
\hline \multicolumn{4}{|l|}{ Hospitalization time } \\
\hline Median with (IQR) & $6(4-8)$ & $12(7-21)$ & 0.071 \\
\hline Serum selenium $[\mu \mathrm{g} / \mathrm{L}]$, mean $\pm \mathrm{SD}$ & $77.9 \pm 14.3 \mu \mathrm{g} / \mathrm{L}$ & $77.2 \pm 12.3 \mu \mathrm{g} / \mathrm{L}$ & $p>.05$ \\
\hline \multicolumn{4}{|l|}{ Laboratory findings } \\
\hline \multicolumn{4}{|l|}{ Median with (IQR) } \\
\hline \multicolumn{4}{|l|}{ No. $(\%)$} \\
\hline White blood cell count, $\times 10^{9} / \mathrm{L}$ & $6.1(4.9-7.9)$ & $6.2(3.9-12.2)$ & 0.851 \\
\hline$<4$ & $5(13.5 \%)$ & $3(23.1 \%)$ & \\
\hline $4-10$ & $28(75.6 \%)$ & $5(38.4 \%)$ & \\
\hline$>10$ & $4(10.9 \%)$ & $5(38.5 \%)$ & \\
\hline Lymphocyte count, $\times 10^{9} / \mathrm{L}$ & $1.2(1-1.6)$ & $0.9(0.6-1.3)$ & 0.037 \\
\hline$<0 \cdot 8$ & $3(8.1 \%)$ & $5(38.5 \%)$ & \\
\hline Neutrophil count, $\times 10^{9} / \mathrm{L}$ & $3.7(2.6-5.4)$ & $4.7(2.8-9.8)$ & 0.162 \\
\hline Neutrophil-to-lymphocyte ratio & $2.2(1.9-4.2)$ & $6.3(4-8.2)$ & $<0.001^{*}$ \\
\hline \multirow[t]{2}{*}{ Platelet count, $\times 10^{9} / \mathrm{L}$} & $194(141-263)$ & $134(105-210)$ & $0.014^{*}$ \\
\hline & $4(10.8 \%)$ & $3(23.1 \%)$ & \\
\hline Lactate dehydrogenase, U/L & $631(430-797)$ & $993(746-1379)$ & \\
\hline$>245$ & $36(97 \%)$ & $12(92.3 \%)$ & $0.015^{*}$ \\
\hline
\end{tabular}

$I Q R$ interquartile range,: number, $S D$ standard deviation.*Significant group difference at $p<0.05$. Data were expressed as median with IQR, mean $\pm \mathrm{SD}$, or numbers and percentages 
COVID-19 patients compared to healthy controls [16]. Another study in China also found that the cure rate of COVID-19 disease was significantly correlated with selenium status [17]. A study conducted in South Korea showed that selenium deficiency in COVID-19 patients may reduce the immune response and cause disease progression [18]. Also, a study in the south Indian population reported that serum selenium levels in COVID-19 patients were lower than in the healthy control group [19]. However, the mean serum selenium level of COVID-19 patients in Golestan province was higher than in other studies. According to the sources of selenium in the soil and water of each region, selenium status is different in various parts of the world. Studies in Golestan province showed that selenium levels were high in the soil, grains, loess, sediments, nail, and serum samples [20-22]. These results may explain the difference in selenium levels in our study with other studies. In this study, there was no significant difference between serum selenium levels in the survivor and non-survivor groups, These results were in contrast to the results of the study in Germany [16]. In this study, the mortality of COVID-19 patients was higher in men and elderly patients. Studies show that the death of COVID-19 patients is associated with factors such as obesity, diabetes, male sex, age, asthma, and other chronic diseases [23]. The association between sex and disease severity may be due to differences in the immune response to viral infection in male and female patients. For instance, $\mathrm{T}$ cell response in female patients is stronger than in male patients. Furthermore, pro-inflammatory factors such as IL-8 and IL-18 are higher in male patients [24]. The association between older age and COVID-19 mortality can be due to age-related dysfunction in T lymphocyte and $\mathrm{B}$ lymphocyte and increased type 2 cytokines production, which leads to impaired control of virus replication and ultimately leads to poor outcome [25]. Selenium is an essential trace element that exerts its main function on the health of the body through selenocysteine in the structure of selenoproteins [26, 27]. Adequate levels of selenium are essential for central nervous system function, male reproduction, endocrine system, muscle function, cardiovascular system, and immune system [28]. Viral infection in host cells increases reactive oxygen species (ROS) formation. Increased ROS lead to oxidative stress and increased oxidative stress enhance viral genome mutations and increase virulent strains. Glutathione peroxidase 1 (GPX1) is a cytosolic selenoprotein with antioxidant and antiviral properties [29]. A study in mice lacking the Gpx1 gene showed that infecting mice with the benign type of RNA coxsackievirus B3 caused mutations in the viral genome, augmented virulence, and myocarditis, this condition was not observed in wild-type mice [30]. Also, both wild-type selenium-deficient mice [30] and Gpx1-/- mice [31] infected with influenza A show an increased inflammatory response and severe lung damage. These results propose that Gpx1, as an enzyme most affected by selenium status, may play a protective role in respiratory viral infections. The factors associated with the severity of COVID-19 disease include exhaustion of NK cells and cytotoxic T lymphocytes (CTL) [32]. Studies show that selenium supplementation increases the proliferation of $\mathrm{T}$ cells and NK cells and the function of the innate immune system [33, 34]. IFN- $\gamma$ and TNF- $\alpha$ secreted by CTL have an antiviral activity to the influenza virus [35]. In infected mice with RNA influenza virus, selenium supplementation increases levels of IFN- $\gamma$ and TNF- $\alpha$ in plasma [36]. Inflammatory factors IL- $1 \beta$ and IL- 6 are the causes of pneumonia. In patients with severe COVID-19 disease, the IL-6 level is high and a high level of IL-6 is associated with mortality of disease [37, 38]. Studies show that in the elderly, greater levels of IL-6 are associated with selenium deficiency [39]. In conditions of selenium deficiency in cell culture, lung epithelial cells infected with influenza type A increase production of IL-6 [40]. Selenium supplementation inhibits the induction of IL-6 in mice under oxidative stress [41]. Furthermore, the IL-6 response is reduced by selenium [10, 42]. Selenium in patients with acute respiratory distress syndrome (ARDS) modulates inflammatory responses and improves the antioxidant capacity of the lungs [43]. Increased coagulation activity may be related to increased mortality in COVID-19 patients [44]. Also, studies have reported that the occurrence of thrombotic complications is high in patients with COVID-19 [45]. Selenium controls the arachidonic acid pathway by regulating the synthesis of thromboxane A2 and pro-inflammatory products of lipoxygenase [46]. Selenium deficiency by increasing the ratio of thromboxane $\mathrm{A} 2$ to prostacyclin may be associated with vasoconstriction and blood coagulation [47]. The prognostic factors in COVID-19 patients are lymphopenia, thrombocytopenia, leukocytosis, neutrophil-to-lymphocyte ratio, and LDH [48, 49]. Studies show that the plasma selenium level is inversely related to clinical markers of infection and inflammation, such as leucocyte count, serum CRP, and serum IL-6 [50]. In this study, there was no significant relationship between selenium and prognostic factors such as lymphopenia, thrombocytopenia, leukocytosis, neutrophil-to-lymphocyte ratio, and LDH in COVID-19 patients.

In summary, this study investigated the selenium levels in COVID-19 patients. The results showed that although serum selenium levels in COVID-19 patients were lower than in the healthy control group, there was no significant relationship between selenium and severity and mortality of COVID-19 disease. Further research is needed on the association of selenium with pathogenic factors in a larger population of COVID-19 patients. 
Acknowledgements The authors would like to thank the Golestan University of Medical Sciences, Gorgan, Iran, for financial supporting and Kavosh medical laboratory for analysis of serum selenium.

Author Contribution Ommolbanin Younesian wrote the paper. Behnaz Khodabakhshi contributed data or analysis tools. Nafiseh Abdolahi contributed data or analysis tools. Alireza Norouzi conceived and designed the analysis. Nasser Behnampour performed the analysis. Sara Hosseinzadeh collected the data. Seyedeh Somayeh Hosseini Alarzi collected the data. Hamidreza Joshaghani wrote the paper and conceived and designed the analysis.

Funding This research is supported by the Laboratory Sciences Research Center, Golestan University of Medical Sciences, Gorgan, Iran.

Data Availability The datasets generated during and/or analyzed during the current study are available from the corresponding author on reasonable request.

\section{Declarations}

Ethics Approval This study was approved by the Ethics Committee of Golestan University of Medical Sciences with an ethics code (IR. GOUMS.REC.1399.297). All procedures performed were in agreement with the principles of the Declaration of Helsinki (1964) and later amendments.

Consent to Participate Informed consent was obtained from all individual participants included in the study.

Consent for Publication Not applicable.

Competing Interests The authors declare no competing interests.

\section{References}

1. Guan W-j, Liang W-h, Zhao Y, Liang H-r, Chen Z-s, Li Y-m, Liu X-q, Chen R-c, Tang C-l, Wang T (2020) Comorbidity and its impact on 1590 patients with COVID-19 in China: a nationwide analysis. Eur Respir J 55(5):2000547. https://doi.org/10.1183/ 13993003.00547-2020

2. Wang B, Li R, Lu Z, Huang Y (2020) Does comorbidity increase the risk of patients with COVID-19: evidence from meta-analysis. Aging (Albany NY) 12(7):6049. https://doi.org/10.18632/aging. 103000

3. Carrasco-Hernandez R, Jácome R, López Vidal Y, Ponce de León S (2017) Are RNA viruses candidate agents for the next global pandemic? A review. ILAR J 58(3):343-358. https://doi.org/10. 1093/ilar/ilx026

4. Lu R, Zhao X, Li J, Niu P, Yang B, Wu H, Wang W, Song H, Huang B, Zhu N (2020) Genomic characterisation and epidemiology of 2019 novel coronavirus: implications for virus origins and receptor binding. Lancet 395(10224):565-574. https://doi.org/10. 1016/S0140-6736(20)30251-8

5. Whitton JL (2002) Immunopathology during coxsackievirus infection. In: Seminars in Immunopathology. vol 2. Springer Science \& Business Media, pp 201-213. https://doi.org/10.1007/ s00281-002-0100-4

6. Chang J (2017) Pathogenesis of ebola viral haemorrhagic fever: TTP-like syndrome associated with hepatic coagulopathy based on "two activation theory of the endothelium." J Prev Infect Control 3:1-7. https://doi.org/10.21767/2471-9668.100029

7. Song P, Li W, Xie J, Hou Y, You C (2020) Cytokine storm induced by SARS-CoV-2. Clin Chim Acta 509:280-287. https://doi.org/ 10.1016/j.cca.2020.06.017

8. Muscogiuri G, Barrea L, Savastano S, Colao A (2020) Nutritional recommendations for CoVID-19 quarantine. Eur J Clin Nutr 74(6):850-851. https://doi.org/10.1038/s41430-020-0635-2

9. Chowdhury AI (2020) Role and effects of micronutrients supplementation in immune system and SARS-Cov-2 (COVID-19). Asian J Immunol 4:47-55

10. Hoffmann PR, Berry MJ (2008) The influence of selenium on immune responses. Mol Nutr Food Res 52(11):1273-1280. https:// doi.org/10.1002/mnfr.200700330

11. Beck MA, Handy J, Levander OA (2004) Host nutritional status: the neglected virulence factor. Trends Microbiol 12(9):417-423. https://doi.org/10.1016/j.tim.2004.07.007

12. Bermano G, Méplan C, Mercer DK, Hesketh JE (2021) Selenium and viral infection: are there lessons for COVID-19? Br J Nutr 125(6):618-627. https://doi.org/10.1017/S0007114520003128

13. Hiffler L, Rakotoambinina B (2020) Selenium and RNA virus interactions: Potential implications for SARS-CoV-2 infection (COVID-19). Front Nutr 7:164. https://doi.org/10.3389/fnut.2020. 00164.eCollection2020

14. Kieliszek M, Lipinski B (2020) Selenium supplementation in the prevention of coronavirus infections (COVID-19). Med Hypotheses 143:109878. https://doi.org/10.1016/j.mehy.2020.109878

15. Jacobson B, Lockitch G (1988) Direct determination of selenium in serum by graphite-furnace atomic absorption spectrometry with deuterium background correction and a reduced palladium modifier: age-specific reference ranges. Clin Chem 34(4):709-714. https://doi.org/10.1093/clinchem/34.4.709

16. Moghaddam A, Heller RA, Sun Q, Seelig J, Cherkezov A, Seibert L, Hackler J, Seemann P, Diegmann J, Pilz M (2020) Selenium deficiency is associated with mortality risk from COVID-19. Nutrients 12(7):2098. https://doi.org/10.3390/nu12072098

17. Zhang J, Taylor EW, Bennett K, Saad R, Rayman MP (2020) Association between regional selenium status and reported outcome of COVID-19 cases in China. Am J Clin Nutr 111(6):12971299. https://doi.org/10.1093/ajcn/nqaa095

18. Im JH, Je YS, Baek J, Chung MH, Kwon HY, Lee JS (2020) Nutritional status of patients with COVID-19. Int J Infect Dis 100:390-393. https://doi.org/10.1016/j.ijid.2020.08.018

19. Majeed M, Nagabhushanam K, Gowda S, Mundkur L (2020) An Exploratory study of selenium status in normal subjects and COVID-19 patients in south Indian population: case for adequate selenium status: selenium status in COVID-19 patients. Nutrition (Burbank, Los Angeles County, Calif) 82:111053. https://doi.org/ 10.1016/j.nut.2020.111053

20. Keshavarzi B, Moore F, Najmeddin A, Rahmani F (2012) The role of selenium and selected trace elements in the etiology of esophageal cancer in high risk Golestan province of Iran. Sci Total Environ 433:89-97. https://doi.org/10.1016/j.scitotenv.2012.04. 033

21. Hashemian M, Murphy G, Etemadi A, Poustchi H, Brockman JD, Kamangar F, Pourshams A, Khoshnia M, Gharavi A, Dawsey SM (2017) Toenail mineral concentration and risk of esophageal squamous cell carcinoma, results from the Golestan Cohort Study. Cancer Med 6(12):3052-3059. https://doi.org/10.1002/cam4.1247

22. Nouraie M, Pourshams A, Kamangar F, Sotoudeh M, Derakhshan MH, Akbari MR, Fakheri H, Zahedi MJ, Caldwell K, Abnet CC (2004) Ecologic study of serum selenium and upper gastrointestinal cancers in Iran. World J Gastroenterol: WJG 10(17):2544. https://doi.org/10.3748/wjg.v10.i17.2544

23. Williamson EJ, Walker AJ, Bhaskaran K, Bacon S, Bates C, Morton CE, Curtis HJ, Mehrkar A, Evans D, Inglesby P (2020) 
Factors associated with COVID-19-related death using OpenSAFELY. Nature 584(7821):430-436. https://doi.org/10.1038/ s41586-020-2521-4

24. Takahashi T, Ellingson MK, Wong P, Israelow B, Lucas C, Klein J, Silva J, Mao T, Oh JE, Tokuyama M (2020) Sex differences in immune responses that underlie COVID-19 disease outcomes. Nature 588(7837):315-320. https://doi.org/10.1038/ s41586-020-2700-3

25 Opal SM, Girard TD, Ely EW (2005) The immunopathogenesis of sepsis in elderly patients. Clinical infectious diseases 41(Supplement_7):S504-S512. https://doi.org/10.1086/432007

26. Gladyshev VN, Arnér ES, Berry MJ, Brigelius-Flohé R, Bruford EA, Burk RF, Carlson BA, Castellano S, Chavatte L, Conrad M (2016) Selenoprotein gene nomenclature. J Biol Chem 291(46):24036-24040. https://doi.org/10.1074/jbc.M116.756155

27. Younesian O, Younesian S, HosseinzadehJoshaghani SHR (2020) Association of selenium and risk of esophageal cancer: a review. Med Lab J 14:1-9. https://doi.org/10.29252/mlj.14.1.1

28. Avery JC, Hoffmann PR (2018) Selenium, selenoproteins, and immunity. Nutrients 10(9):1203. https://doi.org/10.3390/nu100 91203

29. Seale LA, Torres DJ, Berry MJ, Pitts MW (2020) A role for selenium-dependent GPX1 in SARS-CoV-2 virulence. Am J Clin Nutr 112(2):447-448. https://doi.org/10.1093/ajcn/nqaa177

30. Beck MA, Levander OA, Handy J (2003) Selenium deficiency and viral infection. J Nutr 133(5):1463S-1467S. https://doi.org/ $10.1093 / \mathrm{jn} / 133.5 .1463 \mathrm{~S}$

31. Yatmaz S, Seow HJ, Gualano RC, Wong ZX, Stambas J, Selemidis S, Crack PJ, Bozinovski S, Anderson GP, Vlahos R (2013) Glutathione peroxidase-1 reduces influenza $A$ virus-induced lung inflammation. Am J Respir Cell Mol Biol 48(1):17-26. https:// doi.org/10.1165/rcmb.2011-0345OC

32. Zheng M, Gao Y, Wang G, Song G, Liu S, Sun D, Xu Y, Tian Z (2020) Functional exhaustion of antiviral lymphocytes in COVID19 patients. Cell Mol Immunol 17(5):533-535. https://doi.org/10. 1038/s41423-020-0402-2

33. Huang H, Jiao X, Xu Y, Han Q, Jiao W, Liu Y, Li S, Teng X (2019) Dietary selenium supplementation alleviates immune toxicity in the hearts of chickens with lead-added drinking water. Avian Pathol 48(3):230-237. https://doi.org/10.1080/03079457. 2019.1572102

34. Roy M, Kiremidjian-Schumacher L, Wishe H, Cohen M, Stotzky G (1994) Supplementation with selenium and human immune cell functions. II. Effect on cytotoxic lymphocytes and natural killer cells. Biol Trace Elem Res 41:115-127. https://doi.org/10.1007/ BF02917222

35. Kuwano K, Kawashima T, ARAI S, (1993) Antiviral effect of TNF- $\alpha$ and IFN- $\gamma$ secreted from a CD8+ influenza virus-specific CTL clone. Viral Immunol 6(1):1-11. https://doi.org/10.1089/ vim.1993.6.1

36. Yu L, Sun L, Nan Y, Zhu L-Y (2011) Protection from H1N1 influenza virus infections in mice by supplementation with selenium: a comparison with selenium-deficient mice. Biol Trace Elem Res 141(1):254-261. https://doi.org/10.1007/s12011-010-8726-x

37. Conti P, Ronconi G, Caraffa A, Gallenga C, Ross R, Frydas I, Kritas S (2020) Induction of pro-inflammatory cytokines (IL-1 and IL-6) and lung inflammation by Coronavirus-19 (COVI-19 or SARS-CoV-2): anti-inflammatory strategies. J Biol Regul Homeost Agents 34(2):327-331. https://doi.org/10.23812/CONTI-E

38. Wan S, Yi Q, Fan S, Lv J, Zhang X, Guo L, Lang C, Xiao Q, Xiao K, Yi Z (2020) Characteristics of lymphocyte subsets and cytokines in peripheral blood of 123 hospitalized patients with
2019 novel coronavirus pneumonia (NCP). MedRxiv. https://doi. org/10.1101/2020.02.10.20021832

39. Tseng C-K, Ho C-T, Hsu H-S, Lin C-H, Li C-I, Li T-C, Liu C-S, Lin C-C, Lin W-Y (2013) Selenium is inversely associated with interleukin-6 in the elderly. J Nutr Health Aging 17(3):280-284. https://doi.org/10.1007/s12603-012-0376-6

40. Jaspers I, Zhang W, Brighton L, Carson J, Styblo M, Beck M (2007) Selenium deficiency alters epithelial cell morphology and responses to influenza. Free Radical Biol Med 42(12):1826-1837. https://doi.org/10.1016/j.freeradbiomed.2007.03.017

41. Viezeliene D, Beekhof P, Gremmer E, Rodovicius H, Sadauskiene I, Jansen E, Ivanov L (2013) Selective induction of IL-6 by aluminum-induced oxidative stress can be prevented by selenium. J Trace Elem Med Biol 27(3):226-229. https://doi.org/10.1016/j. jtemb.2012.11.001

42. Martitz J, Becker N, Renko K, Stoedter M, Hybsier S, Schomburg L (2015) Gene-specific regulation of hepatic selenoprotein expression by interleukin-6. Metallomics 7(11):1515-1521. https://doi. org/10.1039/c5mt00211g

43. Mahmoodpoor A, Hamishehkar H, Shadvar K, Ostadi Z, Sanaie S, Saghaleini SH, Nader ND (2019) The effect of intravenous selenium on oxidative stress in critically ill patients with acute respiratory distress syndrome. Immunol Invest 48(2):147-159. https://doi.org/10.1080/08820139.2018.1496098

44. Zhou F, Yu T, Du R, Fan G, Liu Y, Liu Z, Xiang J, Wang Y, Song $\mathrm{B}, \mathrm{Gu} \mathrm{X}$ (2020) Clinical course and risk factors for mortality of adult inpatients with COVID-19 in Wuhan, China: a retrospective cohort study. Lancet 395(10229):1054-1062. https://doi.org/10. 1016/S0140-6736(20)30566-3

45. Klok F, Kruip M, Van der Meer N, Arbous M, Gommers D, Kant K, Kaptein F, van Paassen J, Stals M, Huisman M (2020) Incidence of thrombotic complications in critically ill ICU patients with COVID-19. Thromb Res 191:145-147. https://doi.org/10. 1016/j.thromres.2020.04.013

46. Eisenmann CJ, Miller RK (1995) The effect of selenium compounds (selenite, selenate, ebselen) on the production of thromboxane and prostacyclin by the human term placenta in vitro. Toxicol Appl Pharmacol 135(1):18-24. https://doi.org/10.1006/ taap.1995.1204

47. Bae M, Kim H (2020) Mini-review on the roles of vitamin C, vitamin $\mathrm{D}$, and selenium in the immune system against COVID19. Molecules 25(22):5346. https://doi.org/10.3390/molecules2 5225346

48. Pourbagheri-Sigaroodi A, Bashash D, Fateh F, Abolghasemi H (2020) Laboratory findings in COVID-19 diagnosis and prognosis. Clin Chim Acta 510:475-482. https://doi.org/10.1016/j.cca. 2020.08.019

49. Shang W, Dong J, Ren Y, Tian M, Li W, Hu J, Li Y (2020) The value of clinical parameters in predicting the severity of COVID19. J Med Virol 92(10):2188-2192. https://doi.org/10.1002/jmv. 26031

50. Sakr Y, Reinhart K, Bloos F, Marx G, Russwurm S, Bauer M, Brunkhorst F (2007) Time course and relationship between plasma selenium concentrations, systemic inflammatory response, sepsis, and multiorgan failure. Br J Anaesth 98(6):775-784. https://doi.org/10.1093/bja/aem091

Publisher's Note Springer Nature remains neutral with regard to jurisdictional claims in published maps and institutional affiliations. 